\section{(B) OPEN ACCESS}

\title{
Knowledge of human papillomavirus (HPV) testing in the USA, the UK and Australia: an international survey
}

\author{
Rachael H Dodd, ${ }^{1}$ Kirsten J McCaffery, ${ }^{2}$ Laura A V Marlow, ${ }^{1}$ Remo Ostini, ${ }^{3}$ \\ Gregory D Zimet, ${ }^{4}$ Jo Waller ${ }^{1}$
}

- Additional material is published online only. To view please visit the journal online (http://dx.doi.org/10.1136/ sextrans-2013-051402).

${ }^{1}$ Department of Epidemiology \& Public Health, Cancer Research UK Health Behaviour Research Centre, UCL, London, UK

${ }^{2}$ Screening and Test Evaluation Program (STEP) and Centre for Medical Psychology \&

Evidence-based Decisionmaking (CeMPED), Sydney

School of Public Health, The University of Sydney, Sydney,

New South Wales, Australia

${ }^{3}$ Faculty of Health Sciences, Healthy Communities Research Centre, The University of Queensland, Ipswich,

Queensland, Australia ${ }^{4}$ Section of Adolescent Medicine, Indiana University School of Medicine, Health Information \& Translational Sciences, Indianapolis, Indiana, USA

\section{Correspondence to} Dr J Waller, Department of Epidemiology and Public Health, Health Behaviour Research Centre, UCL, Gower Street, London WC1E 6BT, UK; j.waller@ucl.ac.uk

Received 15 October 2013 Revised 22 November 2013 Accepted 8 December 2013 Published Online First 10 January 2014

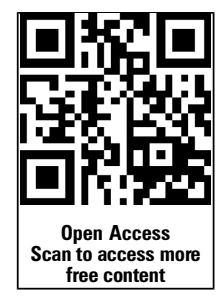

To cite: Dodd RH, McCaffery KJ, Marlow LAV, et al. Sex Transm Infect 2014;90:201-207.
ABSTRACT

Objective To measure knowledge and awareness of human papillomavirus (HPV) testing in the USA, the UK and Australia.

Methods Participants in the USA, UK and Australia completed an anonymous web-based survey measuring awareness and knowledge of HPV $(n=2409)$. We report analyses on a subsample of 1473 men and women in the USA ( $n=617)$, UK ( $n=404)$ and Australia $(n=452)$ who had heard of HPV and completed questions about HPV testing.

Results Overall, $50 \%$ of the sample (742/1473) had heard of HPV testing. Awareness of HPV testing was higher in the USA $(62 \%)$ than in the UK (44\%) and Australia $(40 \%)(p<0.001)$. Among those who had heard of HPV testing, the mean knowledge score (out of 6) was 2.78 (SD: 1.49). No significant differences in knowledge score were found between the countries but, overall, women scored significantly higher than men ( 2.96 vs $2.52, p<0.001$ ).

Conclusions Awareness of HPV testing among people who have heard of HPV is higher in the USA than in the UK and Australia, but overall knowledge is low. This has important implications in those countries where HPV testing is being used in cervical screening. Increasing knowledge about the implications of HPV test results may help minimise any negative psychological consequences associated with HPV testing. Raising awareness in men could become increasingly important if HPV testing is introduced into the management of other cancers where HPV plays an aetiological role.

\section{INTRODUCTION}

Human papillomavirus (HPV) is a common sexually transmitted infection and a necessary agent in the development of cervical cancer, ${ }^{1}$ with high-risk HPV types 16 and 18 implicated in over $70 \%$ of cervical cancer cases. ${ }^{2}$ Testing for high-risk types of HPV is now being used within the cervical screening context around the world. It can be used as a primary screening test and shows higher sensitivity in detecting cervical abnormalities than cytology. ${ }^{3}$ Because of the high prevalence of transient infection in young women, ${ }^{4}$ primary HPV testing in the USA is usually restricted to women aged 30 years and over. ${ }^{5}$ Second, since 2001 in the USA ${ }^{6}$ and 2011 in England, ${ }^{7}$ HPV testing has been used to triage borderline or mildly abnormal cytology results, reducing the number of women on early recall, and speeding up colposcopy follow-up for those with high-risk HPV. Finally, it can be used as a 'test of cure' following treatment. Women who are HPV negative following treatment for cervical abnormalities can safely be returned to routine screening; this is now part of routine practice in the UK and Australia. ${ }^{8-11}$

There is evidence that testing positive for HPV in the cervical screening context can cause anxiety and distress for some women. ${ }^{12-15}$ Those with a positive HPV result at triage initially have worse psychosocial outcomes than those managed by repeat cytology. ${ }^{16}$ In the longer term, however, psychosocial outcomes have been shown to be better in women receiving HPV triage testing than women receiving repeat cytology screening, ${ }^{16}$ and levels of concern about the cytology result are higher in those not tested for HPV at 6-month follow-up. ${ }^{17}$ When informed of the advantages and disadvantages of HPV testing and repeat cytology, and when given the choice of management strategies, women in Australia have shown a preference for HPV testing. ${ }^{16} 18$

Communicating the meaning of HPV test results and the purpose of HPV testing may help alleviate anxiety, distress and concern, and reduce perceived risk of cervical cancer which has been shown to be much higher than actual risk. ${ }^{14}$ As HPV testing is now being widely used in cervical screening, and may be introduced in the context of other HPV-related cancers in the future, ${ }^{19}$ assessing awareness and knowledge of HPV testing is important to identify information needs in women and men. Addressing these needs could help women and men to understand their results and minimise anxiety and distress associated with HPV testing results.

We assessed knowledge about HPV testing across three countries currently using the test in different ways within cervical screening programmes, to see how informed women and men in the general population are, and to identify information gaps overall and in demographic subgroups.

\section{METHODS}

\section{Participants}

A total of 12259 participants were directed by email to a web-based survey through international online respondent panels in the USA, UK and Australia managed by Survey Sampling International (SSI). The target sample in each country was 800 participants, with an even split of men and women in the age range of $18-70$ years. 
Men and women meeting the study criteria were randomly selected and sent recruitment emails containing a link directing them to the home page of our online survey which was entitled 'What do you know about HPV?' The survey was adapted for use in the USA, UK and Australia, changing terminology where appropriate. Further details of the sampling are available elsewhere. $^{20}{ }^{21}$ Ethical approval was granted from research ethics committees at Indiana University, USA, University College London, UK and the University of Sydney, Australia.

\section{Measures}

Participants were given general information about the purpose of the study and the contact details for the researchers in their country of residence. The questionnaire initially asked participants their age, gender and country of residence to check that the quota for their gender $(n=400$ men, $n=400$ women $)$ or country $(n=800)$ was not already full. The first question asked 'Before today, had you ever heard of HPV?' Participants who responded 'yes' were directed to a further 15 questions that assessed knowledge of HPV. Participants were then asked 'Have you ever heard of HPV testing?' Those who responded 'yes' were directed to a further six questions that assessed knowledge of HPV testing. The scale items can be seen in table 3. The development and validation of the scale is described elsewhere. $^{21}$ Response options were true/false/don't know, with 'don't know' scored as incorrect. Participants additionally answered demographic questions and indicated whether they had received the HPV vaccination, and whether they had a daughter aged 9-17 years (the HPV vaccination age-range).

\section{Statistical analysis}

To measure within-country demographic differences between those who were and were not aware of HPV testing, independent $t$ tests were used for age, and $\chi^{2}$ tests were used for the categorical demographic items: sex, relationship status, ethnicity, education, having a daughter aged 9-17 and having had the HPV vaccine. Multivariate logistic regression analyses were conducted to explore independent demographic predictors of HPV testing awareness overall and among men and women within each country. The HPV testing knowledge scores for each country were normally distributed, and so to examine the differences in mean HPV testing knowledge score overall and among men and women within each country, independent $t$ tests were used for demographic variables with two groups, ANOVAs examined differences with more than two groups, and posthoc Tukey's tests were used to establish where the significant differences lay. All $\mathrm{p}$ values of less than 0.05 were considered to be statistically significant. $\chi^{2}$ tests were used to evaluate whether there were differences in the proportion of correct responses to each of the individual HPV-testing knowledge items between men and women overall and within each country. Data were analysed using SPSS V.21.

\section{RESULTS}

\section{Awareness of HPV testing}

Overall, the survey was completed by 2409 men and women in the USA, UK and Australia (see online supplementary figure S1). Of these, 61\% (1473/2409) had heard of HPV (USA: $n=617$, UK: $n=404$, Australia: $n=452)$. In the subsample who were aware of HPV, 50\% (742/1473) had heard of HPV testing

Table 1 Sample characteristics of those who had and had not heard of human papillomavirus (HPV) testing ( $n=1473)$

\begin{tabular}{|c|c|c|c|c|c|c|c|c|c|}
\hline & \multicolumn{3}{|l|}{ USA } & \multicolumn{3}{|l|}{ UK } & \multicolumn{3}{|l|}{ AUS } \\
\hline & $\begin{array}{l}\text { Total heard } \\
\text { of HPV } \\
\text { ( } n=617)\end{array}$ & $\begin{array}{l}\text { Not aware of } \\
\text { HPV testing } \\
(n=234)\end{array}$ & $\begin{array}{l}\text { Aware of } \\
\text { HPV testing } \\
(n=383)\end{array}$ & $\begin{array}{l}\text { Total heard } \\
\text { of HPV } \\
(n=404)\end{array}$ & $\begin{array}{l}\text { Not aware of } \\
\text { HPV testing } \\
(n=227)\end{array}$ & $\begin{array}{l}\text { Aware of } \\
\text { HPV testing } \\
(n=177)\end{array}$ & $\begin{array}{l}\text { Total heard } \\
\text { of HPV } \\
(n=452)\end{array}$ & $\begin{array}{l}\text { Not aware of } \\
\text { HPV testing } \\
(n=270)\end{array}$ & $\begin{array}{l}\text { Aware of } \\
\text { HPV testing } \\
(n=182)\end{array}$ \\
\hline Age (mean (SD)) & 45.12 (15.47) & $48.30(14.5)$ & $43.17(15.8)^{* *}$ & 39.96 (14.17) & $40.62(14.35)$ & 39.12 (13.94) & $47.87(14.73)$ & 47.81 (14.94) & 47.95 (14.46) \\
\hline \multicolumn{10}{|l|}{ Sex (n (\%)) } \\
\hline Male & $253(41.0)$ & $98(41.9)$ & $155(40.5)$ & $155(38.4)$ & $88(38.8)$ & $67(37.9)$ & 164 (36.6) & $87(32.2)$ & $77(42.3)^{*}$ \\
\hline Female & $364(59.0)$ & $136(58.1)$ & $228(59.5)$ & $249(61.6)$ & $139(61.2)$ & $110(62.1)$ & $288(63.7)$ & $183(67.8)$ & $105(57.7)$ \\
\hline \multicolumn{10}{|c|}{ Relationship status (n (\%)) } \\
\hline Single & $201(32.6)$ & $73(31.2)$ & $128(33.4)$ & $128(31.7)$ & $71(31.3)$ & $57(32.2)$ & $120(26.5)$ & $60(22.2)$ & $60(33.0)$ \\
\hline Dating & $51(8.3)$ & $15(6.4)$ & $36(9.4)$ & $43(10.6)$ & $24(10.6)$ & $19(9.7)$ & $34(7.5)$ & $24(8.9)$ & $10(5.5)$ \\
\hline Cohabiting & $50(8.1)$ & $19(8.1)$ & $31(8.1)$ & $69(17.1)$ & $40(17.6)$ & $29(16.4)$ & $67(14.8)$ & $44(16.3)$ & $23(12.6)$ \\
\hline Married & $315(51.1)$ & $127(54.3)$ & $188(49.1)$ & $164(40.6)$ & $92(40.5)$ & $72(40.7)$ & $231(51.1)$ & $142(52.6)$ & 89 (48.9) \\
\hline \multicolumn{10}{|l|}{ Ethnicity† (n (\%)) } \\
\hline Majority & $527(85.4)$ & $199(85.0)$ & $328(85.6)$ & $332(82.2)$ & $196(86.3)$ & $136(76.8)^{*}$ & $347(76.8)$ & $215(79.6)$ & $132(72.5)$ \\
\hline Minority & 90 (14.6) & $35(15.0)$ & 55 (14.4) & $72(17.8)$ & 31 (13.7) & $41(23.2)$ & $105(23.2)$ & $55(20.4)$ & $50(27.5)$ \\
\hline \multicolumn{10}{|l|}{ Education‡ (n (\%)) } \\
\hline High & $248(40.2)$ & $80(34.2)$ & $168(43.9)^{*}$ & $178(44.2)$ & $96(42.3)$ & $82(46.3)$ & $120(26.5)$ & $58(21.5)$ & $62(34.1)^{*}$ \\
\hline Medium & $227(36.8)$ & $84(35.9)$ & $143(37.3)$ & $149(37.0)$ & $82(36.1)$ & $67(37.9)$ & $165(36.5)$ & $103(38.1)$ & $62(34.1)$ \\
\hline Low & $142(23.0)$ & $70(29.9)$ & $72(18.8)$ & $76(18.9)$ & $48(21.1)$ & $28(15.8)$ & $167(36.9)$ & $109(40.4)$ & $58(31.8)$ \\
\hline $\begin{array}{l}\text { Daughter } \\
\text { 9-17 years }\end{array}$ & 85 (13.8) & $36(15.3)$ & $49(12.8)$ & 72 (17.9) & $48(21.1)$ & $24(13.6)$ & 75 (16.6) & $35(13.0)$ & $40(22.1)^{*}$ \\
\hline $\begin{array}{l}\text { Had HPV } \\
\text { vaccine§ }\end{array}$ & $43(11.8)$ & $11(8.1)$ & $32(14.0)$ & $21(8.4)$ & $9(6.5)$ & $12(10.9)$ & $43(14.9)$ & $30(16.4)$ & $13(12.4)$ \\
\hline
\end{tabular}

*Significant at $p<0.05$.

** Significant at $p<0.001$.

†Majority in USA=white non-hispanic, UK=white British, AUS=Australian.

łEducation was coded as follows:

High: college graduate/graduate school (USA), degree/postgraduate degree (UK), any university education (AUS). Medium: some college/associate degree (USA), vocational/A-levels/other qualification<degree (UK), vocational qualification (AUS). Low: high school, Continuing Education Diploma or below (USA); no formal education/GCSEs (UK); no formal education/high school (AUS).

§Women only. 
(USA: $n=383$, UK: $n=177$, Australia: $n=182$ ). Awareness of HPV testing was higher in the USA $(62 \%)$ than the UK $(44 \%)$ and Australia $(40 \%) \quad\left(\chi^{2}(2)=59.22, \quad p<0.001\right)$. We examined associations between demographic variables and awareness of HPV testing within each country (table 1). In the USA, awareness of HPV testing was associated with higher educational level: $44 \%$ of those aware of testing were in the high (college graduate or above) education group, compared with $34 \%$ of those who were unaware $\left(\chi^{2}(2)=11.26\right.$, $\mathrm{p}=0.004)$. There was also a significant association between HPV testing awareness and education level in Australia, with $34 \%$ of those having heard of HPV testing being in the high (any university education) education group compared with $22 \%$ of those who were unaware $\left(\chi^{2}(2)=9.11, p=0.011\right)$. In the UK, there was no association with education. Participants aware of HPV testing in the USA were significantly younger than those not aware: mean age was 43 years and 48 years respectively $(\mathrm{t}(524.1)=4.13, \mathrm{p}<0.001)$. In Australia, there was a significant relationship between awareness of HPV testing and gender, with a higher proportion of respondents aware of HPV testing being men (42\%) compared with those not aware of HPV testing $(32 \%) \quad\left(\chi^{2}(1)=4.78, \quad \mathrm{p}=0.029\right)$. Respondents in Australia who had heard of HPV testing were more likely to have a daughter in the vaccine age-range than those who had not $(22 \%$ vs $13 \%)\left(\chi^{2}(1)=6.52, p=0.011\right)$. In the UK, there was a higher proportion of ethnic minority respondents in the group that was aware of HPV testing $(23 \%)$ compared with the group that was unaware $(14 \%)$ $\left(\chi^{2}(1)=5.51, \quad p=0.019\right)$. Demographic variables showing bivariate associations with awareness of HPV testing were entered into multivariate logistic regression analyses (one for each country) (see table 2).

In subgroup analyses among men and women, some gender differences in the predictors of HPV testing awareness emerged. In US women, awareness of HPV testing was significantly lower in the least educated group $(\mathrm{OR}=0.46,95 \% \mathrm{CI} 0.27$ to 0.80 ) and in the group that had a daughter in the vaccination age range $(\mathrm{OR}=0.48$, 95\% CI 0.25 to 0.90$)$. Among Australian women, having a daughter in the vaccination age range was a significant predictor of HPV testing awareness $(\mathrm{OR}=2.16,95 \%$ CI 1.12 to 4.18). Among Australian men, being from an ethnic minority group was a significant predictor of HPV testing awareness $(\mathrm{OR}=2.17,95 \% \mathrm{CI} 1.04$ to 4.54$)$. There were no gender differences in demographic predictors of HPV testing awareness in the UK.

\section{Responses to individual HPV testing items}

The proportion of respondents giving the correct answer to each individual item is shown in table 3 , with statistical tests and $\mathrm{p}$ values. Across all three countries, there was highest awareness of the fact that a HPV positive result does not mean a woman will definitely develop cervical cancer $(76 \%$ correct overall), although respondents in Australia were less likely to answer this item correctly than those in the USA and UK (65\% Australia vs $79 \%$ USA vs $79 \%$ UK; $\left.\chi^{2}(2)=15.22, \mathrm{p}<0.001\right)$. There was also high awareness that a HPV test can be carried out at the same time as a Pap test $(74 \%$ correct overall). The other four items were answered correctly by fewer than half the respondents, with lowest awareness of the low-risk implications of a HPV negative result $(24 \%$ correct overall). In the UK, men were more likely than women to correctly answer the item that a negative HPV result means a woman's risk of cervical cancer is low (42\% men correct vs $24 \%$ women). In Australia, women were more likely than men to know that you do not get the results the same day when you have a HPV test $(42 \%$ women vs $25 \%$ men).

\section{Knowledge of HPV testing (total scale score)}

Among those who had heard of HPV testing, the mean knowledge score (out of 6) was 2.78 (SD: 1.49). There were no significant differences in knowledge score between countries (mean scores were 2.83 in the USA; 2.91 in the UK; and 2.57 in Australia). Overall, women scored significantly higher than men (2.96 vs $2.52, \mathrm{t}(740)=-3.998, \mathrm{p}<0.001)$.

Table 2 Demographic correlates of awareness of human papillomavirus (HPV) testing (multivariate logistic regression models)

\begin{tabular}{|c|c|c|c|}
\hline & \multicolumn{3}{|l|}{ OR $(95 \% \mathrm{Cl})$} \\
\hline & USA (n=617) & UK $(n=404)$ & AUS ( $n=451)$ \\
\hline Age & $0.98(0.97 \text { to } 0.99)^{* * *}$ & - & - \\
\hline \multicolumn{4}{|l|}{ Relationship status } \\
\hline Single & - & - & $1.73(1.10 \text { to } 2.74)^{*}$ \\
\hline Dating/cohabiting & - & - & $0.79(0.48$ to 1.32$)$ \\
\hline Married (reference) & - & - & 1.00 \\
\hline \multicolumn{4}{|l|}{ Ethnicity $†$} \\
\hline Majority (reference) & - & 1.00 & - \\
\hline Minority & - & $1.91(1.14 \text { to } 3.19)^{*}$ & - \\
\hline \multicolumn{4}{|l|}{ Education $\ddagger$} \\
\hline High (reference) & 1.00 & - & 1.00 \\
\hline Medium & $0.83(0.57$ to 1.22$)$ & - & $0.57(0.35 \text { to } 0.92)^{*}$ \\
\hline Low & $0.49(0.32 \text { to } 0.74)^{* * *}$ & - & $0.53(0.33 \text { to } 0.87)^{* *}$ \\
\hline Have a daughter $9-17$ years & - & - & $1.99(1.19 \text { to } 3.34)^{* *}$ \\
\hline \multicolumn{4}{|c|}{$\begin{array}{l}{ }^{*} p<0.05 . \\
{ }^{* *} p<0.01 . \\
{ }^{* *} p<0.001 . \\
\text { †Majority in USA=white non-hispan } \\
\text { ‡Education was coded as follows: } \\
\text { High: college graduate/graduate sch } \\
\text { qualification }<\text { degree (UK); vocationa }\end{array}$} \\
\hline
\end{tabular}




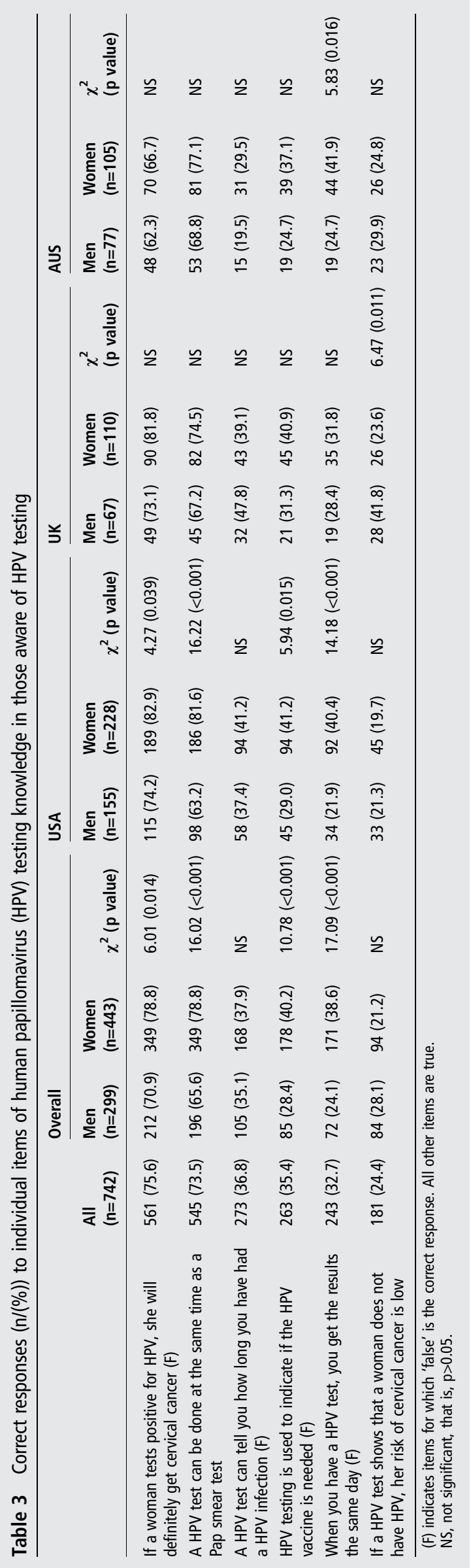

We assessed demographic predictors of higher knowledge scores within each country (see table 4 for statistical tests and $p$ values). Women had significantly higher scores than men in the USA (mean $=3.07$ for women vs 2.47 for men) and Australia (mean=2.77 for women vs 2.30 for men), but there was no gender difference in the UK. In Australia, respondents who were cohabiting (mean $=3.35$ ) had significantly higher scores than those who were married (mean $=2.40$ ), and women who had received the HPV vaccination (mean $=4.08$ ) had significantly higher scores than those who had not (mean=2.59). Knowledge also showed significant associations with education in the USA and the UK, though the pattern of association was not consistent.

In subgroup analyses among men and women, some gender differences in the predictors of HPV testing knowledge emerged. Educational level was significantly associated with HPV testing knowledge among women in the USA $(\mathrm{F}(2,225)$ $=3.49, \mathrm{p}=0.03$ ) but not men, with posthoc analysis showing the difference lay between high and low educational levels (mean $=3.27$ vs $2.61, p=0.02$ ). Relationship status had a significant association with HPV testing knowledge in Australian women $(\mathrm{F}(2,102)=4.32, \mathrm{p}=0.02)$ but not men, with posthoc analysis showing women who were cohabiting were more knowledgeable about HPV testing than married women (mean $=3.67$ vs $2.44, p=0.04$ ). There were no other significant gender differences in associations between demographic variables and HPV testing knowledge.

\section{DISCUSSION}

This study uses a validated measure to assess awareness and knowledge of HPV testing across three countries. Around half of those who had heard of HPV had also heard of HPV testing, demonstrating that awareness of HPV does not imply knowledge of HPV testing. A higher proportion of the sample from the USA had heard of HPV testing compared to the UK and Australia, but this did not translate to greater knowledge about HPV testing. Significant demographic predictors of awareness of HPV testing were younger age and higher education in the USA, being of an ethnic minority group in the UK, and being single, having more education and having a daughter in the HPV vaccination age range in Australia. The education results in the USA and Australia were consistent with previous studies measuring awareness of $\mathrm{HPV}^{22}$ In all three countries, women had higher HPV testing knowledge than men. This would be expected since HPV is commonly associated with cervical cancer, so it is women who are currently referred for HPV testing in the countries included in our study. Previous research on the psychological implications of HPV testing has also focused on women. ${ }^{12} 131618$

The two knowledge items that were consistently answered correctly by the majority of participants across the three countries were that the HPV test can be done at the same time as a Pap test, and that testing positive for HPV does not mean a woman will definitely get cervical cancer, demonstrating some understanding of the implications of HPV test results. However, men and women in all three countries had limited knowledge that: HPV testing is not used to indicate that the HPV vaccine is needed, and if a HPV test shows a woman does not have HPV, that her risk of cervical cancer is low. This corresponds with previous findings that a negative HPV test result is no more reassuring than no HPV test in women with abnormal cytology results, ${ }^{14}$ as women do not understand the implications of the results. This demonstrates where knowledge could be improved, and points to aspects of HPV testing information that could be 
Table 4 Demographic differences in mean human papillomavirus (HPV) testing knowledge

\begin{tabular}{|c|c|c|c|c|c|c|c|c|c|}
\hline & \multicolumn{3}{|c|}{ USA (n=383) } & \multicolumn{3}{|c|}{ UK $(n=177)$} & \multicolumn{3}{|c|}{ AUS $(n=182)$} \\
\hline & $\mathbf{n}$ & $\begin{array}{l}\text { HPV testing } \\
\text { knowledge } \\
\text { (mean (SD)) }\end{array}$ & $\begin{array}{l}\text { Significance } \\
\text { ( } p \text { value) }\end{array}$ & $\mathbf{n}$ & $\begin{array}{l}\text { HPV testing } \\
\text { knowledge } \\
\text { (mean (SD)) }\end{array}$ & $\begin{array}{l}\text { Significance } \\
\text { ( } p \text { value) }\end{array}$ & $\mathbf{n}$ & $\begin{array}{l}\text { HPV testing } \\
\text { knowledge } \\
\text { (mean (SD)) }\end{array}$ & $\begin{array}{l}\text { Significance } \\
\text { ( } p \text { value) }\end{array}$ \\
\hline \multicolumn{10}{|l|}{ Sex (mean (SD)) } \\
\hline Male & 155 & $2.47(1.50)$ & $t(381)=-3.97,(<0.001)$ & 67 & $2.90(1.38)$ & NS & 77 & $2.30(1.51)$ & $t(180)=-2.01,(0.046)$ \\
\hline Female & 228 & $3.07(1.41)$ & & 110 & $2.92(1.39)$ & & 105 & $2.77(1.61)$ & \\
\hline \multicolumn{10}{|c|}{ Relationship status (mean) } \\
\hline Single & 128 & $2.66(1.51)$ & NS & 57 & $3.02(1.49)$ & NS & 60 & $2.37(1.68)$ & $F(3,178)=3.84,(0.011)$ \\
\hline Dating & 36 & $2.67(1.72)$ & & 19 & $3.00(1.45)$ & & 10 & $3.50(1.43)$ & \\
\hline Cohabiting & 31 & $3.35(1.40)$ & & 29 & $3.07(1.25)$ & & 23 & $3.35(1.50)^{*}$ & \\
\hline Married & 188 & $2.89(1.40)$ & & 72 & $2.74(1.33)$ & & 89 & $2.40(1.48)^{*}$ & \\
\hline \multicolumn{10}{|c|}{ Education (mean) } \\
\hline High & 168 & $3.00(1.54)^{*}$ & $F(2,380)=3.80,(0.023)$ & 82 & $3.12(1.30)^{*}$ & $F(2,174)=3.11,(0.047)$ & 62 & $2.77(1.59)$ & NS \\
\hline Medium & 143 & $2.83(1.43)$ & & 67 & $2.58(1.48)^{*}$ & & 62 & $2.63(1.60)$ & \\
\hline Low & 72 & $2.43(1.34)^{*}$ & & 28 & $3.07(1.27)$ & & 58 & $2.29(1.53)$ & \\
\hline \multicolumn{10}{|c|}{ Had HPV vaccine (mean (SD)) } \\
\hline Yes & 32 & $3.31(1.62)$ & NS & 12 & $2.75(1.06)$ & NS & 13 & $4.08(1.55)$ & $\mathrm{t}(103)=3.27,(<0.001)$ \\
\hline No & 96 & $3.03(1.38)$ & & 98 & $2.94(1.43)$ & & 92 & $2.59(1.54)$ & \\
\hline
\end{tabular}

targeted in educational materials. It also suggests that participants seem to be able to interpret the meaning of a positive test result more easily than a negative test result. In the USA, clinicians have been shown to use HPV testing in ways which deviate from the guidelines. ${ }^{23}$ Agreement of how and when HPV testing should be offered, and the key educational messages needed about HPV testing, could be useful to ensure that the information people receive is consistent across sources and congruent with procedures. Interestingly, UK men had higher levels of understanding of the implications of a negative HPV test than women, which may be explained by women's experiences of uncertainty and confusion about the virus translating to a misunderstanding about their results. ${ }^{24}$ There were greater differences in knowledge between US men and women than in the UK and Australia, with US women correctly answering more knowledge items than men. Lower knowledge in Australia may reflect the limited use of HPV testing in comparison to use of HPV testing in the USA and UK.

Australian respondents who had a daughter in the HPV vaccination age range were more likely to have heard of HPV testing than those without a daughter in the HPV vaccination age range. This may be a consequence of parents searching for more information to make an informed decision about vaccinating their daughter, in line with findings from a systematic review of parental knowledge of the HPV vaccination. ${ }^{25}$ When stratifying by gender, the association between having heard of HPV testing and having a daughter in the vaccination age group was significant for women and not men, perhaps reflecting the 'feminisation of $\mathrm{HPV}^{26}$ and the predominantly maternal role in childhood vaccination decisions. Surprisingly, the relationship between having a daughter in the HPV vaccination age range and awareness of HPV testing was not found in the UK, where school-aged girls are also being vaccinated. One possible explanation for this difference from the Australian finding is that the information campaign in the UK promotes the 'cervical cancer vaccine', whereas the Australian information materials call it the
'HPV school vaccination programme'. This may make it harder for women in the UK to understand the link between the HPV vaccine and HPV testing within the screening programme. There is a need to address this knowledge gap in men and women. In the USA, women with a daughter aged 9-17 were less likely to have heard about HPV testing than women without a daughter in the vaccine age range. As there is not a school-based HPV vaccination programme in the USA unlike in the UK and Australia, there may be limited awareness of HPV testing in this subgroup.

Across all UK respondents and in Australian males, those from an ethnic minority group were more likely to be aware of HPV testing, contrasting with findings of awareness of HPV from previous literature. ${ }^{27} 28$ This may reflect our use of a webbased survey and may not translate into clinically significant findings. A similarly surprising finding was the higher awareness of HPV testing in men than women in Australia, although women were more likely to have heard of HPV. Additionally, a greater number of Australian males with higher educational levels had heard of HPV testing than the equivalent group for women. This may be due to men preferring to indicate that they have heard of HPV testing rather than admitting that they have not, corroborating previous research finding men to overestimate their performance in knowledge tests. ${ }^{29}$ This would also be consistent with our finding that women were more knowledgeable than men on the knowledge scale for HPV testing, despite their lower self-reported awareness levels.

The differing levels of knowledge and awareness of HPV testing highlights the need for targeted awareness strategies in those countries where HPV testing is now being implemented. Knowledge and awareness could be improved through ensuring that information is accessible to those with lower education levels, for example, through not limiting information to written materials, encouraging discussion about HPV testing in the media and incorporating information about HPV and the implications of HPV test results in community outreach initiatives. 
This could help reduce the anxiety and distress in women following HPV testing. ${ }^{12-14}$ Women need to be aware of the implications of the results of HPV testing and what this may mean for future treatment. Offering an educational intervention has been shown to reduce concern in women testing positive for HPV. $^{30}$ Men also need to be made more aware of HPV testing as this is being recommended as part of the clinical management of HPV-related non-cervical cancers (eg, oropharyngeal squamous cell carcinoma) ${ }^{19}$ and some clinicians in the USA are already providing 'off-label' HPV testing for men. ${ }^{31}$

By recruiting online, we were able to directly compare samples across the three countries using a validated measure of HPV testing knowledge, ${ }^{21}$ which allows for comparison in future studies. The use of quotas ensured that respondents with lower levels of education were well represented. The sample was limited to three countries, and participants were recruited from online panels with set quota sampling methods, and so may not be representative of the population. Caution should also be exercised in generalising these results to other countries. Additionally, only those who had heard of HPV were included in our analyses, so some of the demographic associations may not generalise to the wider population. For example, although awareness of HPV testing was higher in Australian men than women in our sample, this could be misleading as more Australian women are aware of HPV itself. ${ }^{20}$ The sample was drawn from internet users which may have introduced some bias.

It is important that people understand why they are being offered HPV testing and what the test results mean. Our study provides an indication of current knowledge about HPV testing and understanding of test results in three countries where HPV testing is being used for different purposes. Our findings could be used to inform the development of information materials to accompany HPV testing in cervical screening programmes.

\section{Key messages}

- Overall knowledge of human papillomavirus (HPV) testing is low in the USA, the UK and Australia.

- Targeted knowledge and awareness strategies are needed in countries where HPV testing is being implemented.

- Increasing understanding around the implications of a negative HPV test result may help minimise any negative psychological consequences associated with the test.

- Men need to be made more aware of HPV testing as it may be introduced into management of other HPV-related cancers.

\section{Handling editor Jackie A Cassell}

Acknowledgements We are grateful to all the study participants.

Contributors KJM, LAVM, RO, GDZ and JW contributed to the planning and design of the study. RHD and JW drafted the article. LAVM assembled the data and RHD performed the statistical analysis. RHD and JW interpreted the data. All authors assisted with revisions of the article, read and approved the final article.

Funding Funding for data collection came from departmental funds from the Section of Adolescent Medicine, Department of Pediatrics, Indiana University and the Cancer Research UK Health Behaviour Research Centre, Department of Epidemiology and Public Health, UCL.

Competing interests GDZ is an investigator on investigator-initiated grants funded by Merck and Co. GDZ is also a recipient of an unrestricted programme development grant from GlaxoSmithKline.
Ethics approval Indiana University, USA; University College London, UK; University of Sydney, Australia.

Provenance and peer review Not commissioned; externally peer reviewed.

Data sharing statement There are some other variables for which data will be analysed which is currently available within our collaborative group. Once we have published it, we will consider sharing the dataset with interested researchers who want to reanalyse it for other purposes.

Open Access This is an Open Access article distributed in accordance with the Creative Commons Attribution Non Commercial (CC BY-NC 3.0) license, which permits others to distribute, remix, adapt, build upon this work non-commercially, and license their derivative works on different terms, provided the original work is properly cited and the use is non-commercial. See: http://creativecommons.org/ licenses/by-nc/3.0/

\section{REFERENCES}

1 Bosch FX, Munoz N. The viral etiology of cervical cancer. Virus Res 2002:89:183-90.

2 Munoz N, Bosch FX, Castellsague X, et al. Against which human papillomavirus types shall we vaccinate and screen? The international perspective. Int J Cancer 2004;111:278-85.

3 Cuzick J, Clavel C, Petry KU, et al. Overview of the European and North American studies on HPV testing in primary cervical cancer screening. Int J Cancer 2006;119:1095-101.

4 Woodman CBJ, Collins S, Winter $\mathrm{H}$, et al. Natural history of cervical human papillomavirus infection in young women: a longitudinal cohort study. Lancet 2001;357:1831-6.

5 Moyer VA. Screening for cervical cancer: U.S. Preventative Services Task Force Recommendation Statement. Ann Intern Med 2012;156:880-91.

6 Wright TC, Cox JT, Massad LS, et al. 2001 Consensus guidelines for the management of women with cervical cytological abnormalities. JAMA 2002;287:2120-9.

7 Kelly RS, Patnick J, Kitchener HC, et al. HPV testing as a triage for borderline or mild dyskaryosis on cervical cytology: results from the Sentinel Sites study. $\mathrm{Br} J$ Cancer 2011;105:983-8.

8 Australian Government Department of Health and Ageing. HPV DNA Testing. http:// www.cancerscreening.gov.au/internet/screening/publishing.nsf/Content/hpv-testing/ (accessed 31 Jan 2013).

9 Albrow R, Kitchener H, Gupta N, et al. Cervical screening in England: the past, present, and future. Cancer Cytopathol 2012;120:87-96.

10 National Cancer Screening Programmes. HPV triage and test of cure in the cervical screening programme in England. http://www.cancerscreening.nhs.uk/cervical/ hpv-triage-test-of-cure.html (accessed 13 Jun 2013).

11 Australian Government National Health and Medical Research Council. Screening to prevent cervical cancer: guidelines for the management of asymptomatic women with screen detected abnormalities. 2005. http://www.nhmrc.gov.au/_files_nhmrc/ publications/attachments/wh39.pdf (accessed 17 Jul 2013).

12 McCaffery $\mathrm{K}$, Waller J, Forrest $\mathrm{S}$, et al. Testing positive for human papillomavirus in routine cervical screening: examination of psychosocial impact. BJOG 2004;111:1437-43.

13 McCaffery K, Waller J, Nazroo J, et al. Social and psychological impact of HPV testing in cervical screening: a qualitative study. Sex Transm Infect 2006;82:169-74

14 Maissi E, Marteau TM, Hankins M, et al. Psychological impact of human papillomavirus testing in women with borderline or mildly dyskaryotic cervical smear test results: cross sectional questionnaire study. BMJ 2004;328:1-6.

15 Daley EM, Perrin KM, McDermott RJ, et al. The psychosocial burden of HPV: a mixed-method study of knowledge, attitudes and behaviors among HPV+ women. J Health Psychol 2010;15:279-90.

16 McCaffery KJ, Irwig L, Turner R, et al. Psychosocial outcomes of three triage methods for the management of borderline abnormal cervical smears: an open randomised trial. BMJ 2010;340:b4491.

17 Maissi E, Marteau TM, Hankins M, et al. The psychological impact of human papillomavirus testing in women with borderline or mildly dyskaryotic cervical smear test results: 6-month follow-up. Br J Cancer 2005;92:990-4.

18 McCaffery KJ, Irwig L, Chan SF, et al. HPV testing versus repeat Pap testing for the management of a minor abnormal Pap smear: evaluation of a decision aid to support informed choice. Patient Educ Couns 2008;73:473-9, 81

19 Robinson M, Schache A, Sloan P, et al. HPV specific testing: a requirement for oropharyngeal squamous cell carcinoma patients. Head Neck Pathol 2012;6(Suppl 1):S83-90.

20 Marlow LA, Zimet GD, McCaffery KJ, et al. Knowledge of human papillomavirus (HPV) and HPV vaccination: an international comparison. Vaccine 2013;31:763-9.

21 Waller J, Ostini R, Marlow LA, et al. Validation of a measure of knowledge about human papillomavirus (HPV) using item response theory and classical test theory. Prev Med 2013:56:35-40. 
22 Marlow LA, Waller J, Wardle J. Public awareness that HPV is a risk factor for cervical cancer. Br J Cancer 2007;97:691-4.

23 Hirth JM, Tan A, Wilkinson GS, et al. Compliance with cervical cancer screening and human papillomavirus testing guidelines among insured young women. Am J Obstet Gynecol 2013:209:200.e1-7

24 Waller J, McCaffery K, Nazroo J, et al. Making sense of information about HPV in cervical screening: a qualitative study. Br J Cancer 2005;92:265-70.

25 Trim K, Nagji N, Elit L, et al. Parental knowledge, attitudes, and behaviours towards human papillomavirus vaccination for their children: a systematic review from 2001 to 2011. Obstet Gynecol Int 2012;2012:921236.

26 Daley EM, Buhi ER, Vaoms CA, et al. Deconstructing the feminization of HPV: why HPV should matter to men. 2012. https://apha.confex.com/apha/140am/ webprogram/Paper264101.html (accessed 12 Jul 2013).
27 Marlow LA, Wardle J, Forster AS, et al. Ethnic differences in human papillomavirus awareness and vaccine acceptability. J Epidemiol Community Health 2009;63:1010-15.

28 Marlow LA. HPV vaccination among ethnic minorities in the UK: knowledge, acceptability and attitudes. Br J Cancer 2011;105:486-92.

29 Macbeth G, De Kohan NC, Razumiejczyk E, et al. Overconfidence and underconfidence biases in general knowledge tasks. Acta Psiquiatr Psicol Am Lat 2006;52:221-6.

30 Papa D, Moore Simas TA, Reynolds M, et al. Assessing the role of education in women's knowledge and acceptance of adjunct high-risk human papillomavirus testing for cervical cancer screening. J Low Genit Tract Dis 2009;13:66-71.

31 Jain $\mathrm{N}$, Irwin K, Carlin L, et al. Use of DNA tests for human Papillomavirus infection by US clinicians, 2004. J Infect Dis 2007;196:76-81. 